\title{
OBSOLESCENCIA Y REVITALIZACIÓN DE UN PARQUE. ACCIÓN COLECTIVA, COGNICIÓN Y CIUDADANÍA EN LA APROPIACIÓN DEL ESPACIO PÚBLICO*
}

\author{
OBSOLESCENCE AND REVITALIZATION OF A PARK. COLLECTIVE ACTION, \\ COGNITION AND CITIZENSHIP IN THE APPROPRIATION OF PUBLIC SPACE
}

\author{
Manuel Felipe García-Arias** \\ Gregorio Hernández-Pulgarín**
}

\begin{abstract}
Resumen
Objetivo. Analizamos las transformaciones de un espacio público en Manizales, Colombia, mostrando cómo la acción colectiva que se materializa en sus usos y algunos procesos cognitivos que permiten representarlo, influyen en la manera en que es apropiado. Metodología. Partimos de una aproximación etnográfica a un parque urbano entre 2016 y 2017. Resultados. La idea de parque como espacio obsoleto que se hacen sus habitantes y usuarios, obedece a la valoración simbólica de las transformaciones materiales asociadas al deterioro y de los cambios de usuarios y usos. Asimismo, evidenciamos que un cambio en la apropiación del lugar a través de la acción colectiva incide en su valoración simbólica y en su revitalización. Conclusiones. Los espacios públicos son escenarios de confluencia compleja y conflictiva de actores que a través de sus diversas formas de apropiación ponen en juego la ciudadanía, pero también la vitalidad de los lugares.
\end{abstract}

Palabras clave: espacio público, apropiación, obsolescencia territorial, revitalización del espacio, acción colectiva

\begin{abstract}
Objective. To analyze the transformation of a public space in Manizales, Colombia, showing how collective action materialized in its uses and in some cognitive processes that allow representing it influence the way in which it is appropriated. Methodology. The methodology used started from an ethnographic approach to an urban park between 2016 and 2017. Results. The idea of the park as an obsolete space made by its inhabitants and users is due to the symbolic value of the material transformations associated with deterioration and changes in users and uses. Likewise, it was also evidenced that a change in the appropriation of the site, through collective action, affects its symbolic valuation and its revitalization. Conclusions. Public spaces are scenarios of complex and conflicting confluence of actors that, through their diverse forms of appropriation, put at stake citizenship, but also the vitality of places.
\end{abstract}

Key words: public space, appropriation, territorial obsolescence, revitalization of space, collective action

\footnotetext{
* Proyecto: "Obsolescencia y deterioro en el barrio Santos, Manizales 2016-2017. Práctica de Investigación II, Programa de Antropología, Universidad de Caldas-Colombia, 2017.

${ }^{* *}$ Universidad de Caldas. Manizales, Colombia. E-mail: manuelnz11@hotmail.com

(1) orcid.org/0000-0001-5198-7405 Google Scholar

${ }^{* * *}$ Universidad de Caldas. Manizales, Colombia. E-mail: gregorio.hernandez@ucaldas.edu.co

(1) orcid.org/0000-0002-9659-4063 Google Scholar
} 


\section{Introducción}

Los espacios públicos de las ciudades contemporáneas se transforman constantemente, tanto en su estructura física perceptible como en los usos que sugieren diferentes dinámicas sociales de apropiación. En dicha transformación juegan un papel clave diferentes aspectos: las mutaciones del espacio físico que obedecen al desgaste connotadas comúnmente como deterioro, algo que suele ser de interés central para la planificación urbana, encargada de mantener las condiciones de usabilidad de los equipamientos urbanos y de otras estructuras que conforman dichos espacios públicos. Pero también hay otras dimensiones de ese cambio que son de interés en este artículo, así como para una rama de los estudios urbanos centrados en el análisis de los dispositivos sociológicos o antropológicos que intervienen en la configuración de los espacios públicos. Nos referimos, por un lado a la "obsolescencia”, entendida no como una cualidad intrínseca de la materialidad urbana, sino como el producto de la valoración simbólica que realizan diferentes actores de un espacio público, de su materialidad y de sus usos. En segundo lugar, hacemos alusión a las mutaciones generadas por la calidad y cantidad de las prácticas de apropiación social y políticas que actores individuales y colectivos, en su calidad de urbanitas y de ciudadanos, hacen del espacio público, algo que es fundamental para evaluar el funcionamiento de un lugar público en una dimensión de tiempo extendida.

Nuestra reflexión sobre este tipo de transformaciones no se enfoca en espacios genéricos. Nos basamos en las mutaciones experimentadas por un espacio urbano, diseñado en función del ocio, en una ciudad intermedia latinoamericana, Manizales- Colombia, algo que sin duda le confiere un matiz a las dinámicas que pretendemos estudiar. Más específicamente, analizamos un escenario público como un parque ubicado en un sector popular de la ciudad, el cual refleja una transición en función de los usos y concepciones que se tienen de éste. A través de una lectura en clave etnográfica de estas transiciones, afirmamos que la condición de novedoso, obsoleto y revitalizado de un espacio público urbano como un parque, dependen no solamente de su materialidad y del papel que cumple en su mantenimiento la municipalidad, sino de un complejo entramado de relaciones sociales y políticas de actores locales en este espacio, así como de la puesta en funcionamiento de mecanismos de valoración simbólica del espacio por parte de usuarios, transeúntes y vecinos del parque.

Autores como Obando y Salcedo ofrecen una definición de los parques que funge como punto de partida para entender nuestro propósito. Para ellos

Los parques son espacios que deben ser políticamente abiertos para todos. Y arquitectónicamente deben posibilitar una multiplicidad de usos. Pero socialmente no son universales, ya que los parques son espacios urbanos producidos por ciertos grupos de ciudadanos que en ciertas ocasiones infortunadas pertenecen a la delincuencia. Esta 
circunstancia lleva a que los parques puedan ser concebidos por los habitantes de una ciudad como extraños a ellos, así como algo que no les pertenece y hasta ni les concierne. (Obando y Salcedo, 2015, p.52)

Empleando otros términos, se puede plantear que la representación sobre los aspectos urbanísticos y arquitectónicos que participa en la definición de un parque, así como de su vida social, es relativa a un conjunto de actores, antes que universal. De lo anterior se colige que las representaciones que llevan a calificar un parque como inseguro para un tipo de sus usuarios o frecuentadores, no lo es para otros que lo pueden emplear para usos no convencionales, es decir, para formas de apropiación, en este caso de ocio, ilegítimas o ilegales; en otros términos, este tipo de usos suelen no ser coherentes con la funcionalidad del diseño originario del espacio público y con los usos de las poblaciones mayoritarias que se supone deben apropiárselo.

Es ahí donde se manifiesta la importancia de entender los procesos socioculturales y políticos que se entretejen detrás de los espacios públicos en una dimensión temporal que permita ver diferentes momentos y formas de apropiación. A través de la lectura de diferentes momentos en los que un parque es apropiado por tipos de actores y acciones disímiles, accedemos a diferentes versiones reivindicatorias del ejercicio de la ciudadanía, a través de manifestaciones alternativas del disfrute de lo público.

\section{Marco Teórico}

\section{Reflexiones sobre los usos, concepciones y apropiaciones de los espacios públicos urbanos}

Algunas lecturas que se hacen del concepto de espacio público plantean que esta noción ha perdido especificidad llegando a ser restrictivo dado su marcado carácter espacialista, producto de las concepciones del urbanismo moderno. La noción de espacio público es fluctuante en función de los intereseses de quienes aborden la realidad que refiere. En ocasiones se hace énfasis en su carácter de espacios que sirven para el encuentro y tránsito de personas (Burbano, 2014), algo que puede incluir la plaza, el parque, la calle, el centro comercial, el café, el bar, etc. (Obando y Salcedo, 2015). Otros, además destacan los intercambios que favorece y lo conciben como un "dispositivo topográfico y social capaz de hacer eficaz al máximo el encuentro y el intercambio entre los hombres” (Gamboa, 2003, p.13)

Así como la noción de opinión pública, la de espacio público puede referirse a la "esfera pública”, allí donde la sociedad desafía al Estado, estableciéndolo como un espacio de libertad. Para los propósitos de nuestro análisis, el espacio público no se agota ni está asociado únicamente a lo físico-espacial (plaza o parque), sea de una unidad (un parque) o de un sistema de espacios. Es, más bien, un ámbito contenedor de la conflictividad social, un espacio complejo 
de reivindicación de la ciudadanía que contiene distintas significaciones dependiendo de la coyuntura y de la ciudad de que se trate.

Los lugares púbicos pueden crecer, presentar un apogeo y declinar en la medida en que el espacio, la actividad o los edificios adquieren o pierden significado (Lamizet, 2002; Piveteau, 1995). El espacio público cuando es utilizado para comunicar transmite símbolos que, a la vez, son compartidos y contribuyen a diferenciar los usos que se hacen del lugar y que generan pertenencia con el mismo (Lamizet, 2002); en este sentido es que se construye la apropiación del espacio público.

Con el tiempo, las prácticas vienen a proporcionarle identidad a los lugares más allá de las intencionalidades que les quieren atribuir sus diseñadores (Delgado, 2015; Monnet, 1998). Low (2009) mostraba como en sus ejemplos de la Plaza de la Cultura y de la Plaza Central en San José de Costa Rica, la contradicción existente entre los propósitos nunca neutrales de la planificación de los espacios públicos cuando se busca su revitalización y la recepción que tienen entre los pobladores.

Uría (2001) en su análisis sobre lugares para el ocio en ciudades españolas, plantea que los espacios públicos - en el caso concreto de los espacios recreativos- no pueden considerarse, territorios neutros o pasivos sino construcciones de agentes sociales activos, que pueden reflejar y reproducir, a la vez que estimular o retardar determinadas dinámicas sociales. Afirma que para adaptarse a la nueva realidad de la sociedad contemporánea, este tipo de espacios se redefinen en un nuevo contexto, cuando no se crean ex novo o se transforman a tal punto que desembocan en tipos claramente desviados de sus puntos de origen anteriores.

Así las cosas, aunque se pretenda definir la identidad de un parque o de una plaza apelando a la atribución de cualidades estéticas de su diseño que los diseñadores esperan comunique ciertos sentidos a sus usuarios, las prácticas de apropiación son realmente las que le asignan su identidad, con independencia a veces de las pretensiones de los planificadores. Otros autores en Colombia (Páramo y Burbano, 2014; Páramo y García, 2010; Páramo y Arroyo, 2014) abordan la otra cara de la moneda, la cual no se puede desdeñar en un análisis del espacio público diseñado: la materialidad del espacio -el escenario de la interacción diría el sociólogo Goffman (2000)- condiciona las actuaciones de los usuarios. Así en este artículo, consideramos que "los usos y las prácticas no ocurren en el vacío, por lo que resulta importante explorar el dominio que despliega la configuración espacial del lugar como facilitador de las prácticas y los usos que dan inicio a un diseño espacial” (Páramo y Burbano, 2014, p. 8).

Las dos cualidades del espacio público señaladas anteriormente son importantes para entender la transición de un espacio como un parque que pasa de ser novedoso a obsoleto, para posteriormente ser revitalizado como el caso que es objeto de análisis en este artículo. Así las 
cosas, siguiendo el argumento de Low (2009), no es neutral, en términos de ocio, el diseño de un parque para usos convencionales. Este es pensado para prácticas de ocio lícitas y sobre todo legítimas, de acuerdo con los parámetros morales de los planificadores. Estos espacios cuando se inauguran obedecen a un uso convencional que restringe el acceso a los sujetos sociales sobre los que recae, por ejemplo, el estigma de consumidores de sustancias psicotrópicas o de "vagos". Es esa carga ideológica que excluye a un tipo de usuarios la que puede funcionar para definir la identidad del parque. Posteriormente, cuando el parque no se corresponde en sus usos con esa identidad y empieza a ser apropiado por los que antes eran excluidos, por usuarios no convencionales, se expresa una contradicción entre los usos del diseño y los usos reales que afectan la identidad del espacio que puede ser pensado como "obsoleto", "deteriorado" o "peligroso". En otro momento el espacio público puede ser intervenido por los diseñadores urbanos o por otros actores, que intentan restituir su uso convencional.

Por otro lado, intriga que sea corriente el empleo de nociones de espacio público en el contexto de la planificación urbana y a veces en ámbitos académicos que se construyen en detrimento de otras que podrían considerarse más oportunas a la hora de mostrar la pluralidad de usos, significados y funciones de un espacio de y para los encuentros y las intersecciones.

El reconocimiento o la negación de dicha pluralidad, incluso de los marginados, excluidos y estigmatizados socialmente, trasciende el importante ámbito de los derechos y se inserta en el de las lecturas que los actores individuales y colectivos suelen hacer de los otros en los escenarios públicos que son construidos como territorios, siempre para grupos específicos. Delgado (2015), a este respecto afirma:

\begin{abstract}
Reconozcamos, de entrada que, dejando de lado su acepción jurídica como espacio de titularidad pública, es decir, propiedad del Estado y sobre el que sólo el Estado tiene autoridad, la idea de espacio público, tal y como se aplica en la actualidad, trasciende de largo la distinción básica entre público y privado, que se limitaría a identificar el espacio público como espacio de visibilidad generalizada, en la que los copresentes forman una sociedad por así decirlo óptica, en la medida en que cada una de sus acciones está sometida a la consideración de los demás, territorio por tanto de exposición, en el doble sentido de exhibición y de riesgo. (p. 57)
\end{abstract}

La discusión y el análisis de este tipo de espacios públicos, como un parque, es de importancia central, no solo en los países del primer mundo, sino también en las ciudades latinoamericanas, por una razón señalada por algunos urbanistas calificados como post-modernos. Algunos de ellos afirman que en el último tiempo el espacio público ha estado desvaneciéndose (Carrasco, 2011; Janoschka, 2002; Salcedo, 2002). Según su perspectiva, los espacios públicos, definidos como lugares de construcción de ciudadanía y encuentro social, han sido al menos parcialmente sustituidos por espacios pseudo-públicos. Así las cosas, 


\begin{abstract}
Si el espacio público moderno significaba exposición, debate crítico, interacción entre clases y autenticidad, su existencia ha sido cuestionada por la nueva sociedad informacional y la ideología privatista que la acompaña: el habitar tradicional ha sido reemplazado por condominios y otras formas de comunidades enrejadas y el mercado ha sido completamente reemplazado por el mall, al menos en el imaginario colectivo. (Salcedo, 2002, p.6)
\end{abstract}

En función de lo anterior, escenarios de naturaleza pública como parques que se transforman en sus usos y en la manera en que son evaluados y vividos, permiten ver encuentros y desencuentros sociales, estrategias de apropiación de diferentes actores urbanos que van más allá de la reivindicación de un espacio y tienden a la reivindicación de la ciudadanía, siempre bajo parámetros morales o ideológicos provistos por la cultura.

\title{
Metodología
}

Este análisis de las transiciones en la estructura física de un parque, pero sobre todo de las transformaciones en materia de apropiación y de la interpretación cognitiva que se hace de dicho espacio, se llevó a cabo a través de una aproximación etnográfica realizada entre los meses de agosto de 2016 y agosto de 2017. El diseño metodológico de este estudio se dividió en tres momentos. En un primer momento se recabó información de fuentes primarias y secundarias tales como los diarios locales, planes de desarrollo de las administraciones municipales del año 2000 hasta la actualidad, documentación de los archivos históricos barriales (aclarando que para el caso del barrio estudiado, la junta de acción comunal no posee un archivo comunal), así como la búsqueda de cartografía municipal. En segundo lugar se realizó la fase de campo. Durante esta fase, desde una visión etnográfica, se diseñaron y realizaron talleres cartográficos con actores estratégicos como líderes locales, representantes de la junta de acción comunal y en general con los habitantes del barrio. Estos talleres fueron unas de las actividades centrales que aportaron a la recolección de información y concreción de los datos. De igual forma se aplicó la observación participante y directa, por tres o cuatro días a la semana durante un año, alternando con la aplicación de entrevistas a los habitantes del barrio. En tercer y último lugar, con la información de campo obtenida, más la revisión de fuentes primarias y secundarias, se llevó a cabo la sistematización y el análisis de la información dando como resultado una reflexión conceptual y empírica que permite entender un fragmento de la realidad cambiante concerniente a los usos sociales de espacios públicos anodinos y habituales como un parque urbano.

Las categorías que orientaron el análisis se derivaron tanto de la revisión conceptual de la temática, como de una depuración a la luz de los resultados del trabajo de campo. Las categorías privilegiadas son producción y apropiación del espacio público, usos y concepciones espacio público, acción colectiva, obsolescencia territorial y revitalización del espacio público. 


\section{Resultados}

\section{Primer momento: de la fundación del lugar al deterioro y la obsolescencia}

Nuestra empresa etnográfica se ubica en un sector compuesto por disímiles unidades habitacionales que poseen diferentes nombres pero que comparten los mismos espacios públicos. Es el caso del barrio Santos de la ciudad de Manizales, una ciudad enclavada en los Andes centro-occidentales de Colombia. El barrio Santos se localiza al sur de la ciudad. Alberga una población de clase media-baja, lo cual equivale, en el sistema de clasificación imperante en Colombia para tasar las tarifas de los pagos de servicios público, a estrato tres, en una escala en la que el estrato uno (1) corresponde a la población de menos ingresos y el seis (6) a la de mayores ingresos.

El barrio limita al sur con la vía Panamericana, al norte con el Barrio la Isabela, al oriente con el Barrio Camilo Torres y al occidente con el Barrio el Guamal. Su fundación data de 1998', año en el cual se empezaron a entregar las primeras viviendas, junto a equipamientos públicos como el parque y las canchas que son objeto de indagación en este artículo, al igual que una única vía que conecta al barrio con otros sectores de la ciudad, la cual es utilizada para el moderado flujo de peatones, motociclistas y automóviles que caracteriza el sector.

Los espacios públicos de interés en este análisis, aunque se encuentran en el barrio Santos, son comunes a otro sector conocido como los conjuntos de Villamercedes, el Mirador del Cable y el conjunto Santo-Domingo, los cuales se encuentran en los borrosos confines del barrio Santos, o allende estos límites, según quien trate de definirlos. El espacio público en el que analizamos transformaciones, en virtud de las concepciones que recaen sobre él, así como por sus usos y usuarios a lo largo de cerca de dos décadas, se concreta en tres equipamientos: dos canchas y un parque infantil. Las canchas son escenarios que en sus comienzos experimentaron frecuente actividad deportiva, en torno a la práctica del microfútbol y del baloncesto, dos deportes que los planificadores suponen apropiados para estos espacios. Así lo dejan entrever las entrevistas realizadas a los dirigentes comunales salientes de su cargo; manifestaban que el barrio contaba con excelentes líderes deportivos y sociales; a lo que se le sumaba que para la época existía una gran reciprocidad e integración entre las familias del barrio.

El parque infantil es el otro equipamiento que fue de uso frecuente en sus albores. Según los relatos, los niños, acompañados por sus padres solían visitarlo sobre todo en horarios alternos a los de la escuela y con manifiesta frecuencia los fines de semana. El estado del equipamiento, las estructuras metálicas de los juegos estaba en buenas condiciones, lo que permitía un uso a su máxima capacidad y resultaba atractivo para usuarios y acompañantes.

\footnotetext{
${ }^{1}$ Respecto a los orígenes de este barrio, "Las primeras casas del barrio Santos, vecino de Guamal, las entregaron en junio de 1998. La urbanización nació como un plan de vivienda para beneficiar a familias de escasos recursos, accediendo a préstamos y a subsidios" (La Patria, 2013).
} 
El número de usuarios potenciales del parque se incrementó en la medida en que fueron construyéndose el resto de unidades residenciales que hacen parte del sector; se hizo más grande la población ${ }^{2}$, pero los espacios públicos siguieron siendo los mismos.

Antes de dar inicio al trabajo de campo ya contábamos con algunas nociones previas que apuntaban a que la zona del parque era el lugar donde por naturaleza los habitantes del sector se encontraban, compartían y dinamizaban la vida comunitaria. Lo anterior gracias en parte a la experiencia personal de uno de los investigadores, que tuvo que ser compartida y analizada reflexivamente por los dos para incluirla como dato.

Esas experiencias sistematizadas coincidían con los relatos de quienes habían sido habitantes los del sector desde su fundación. Coincidían en las entrevistas en que durante los primero años de ambos espacios los equipamientos eran de calidad y que eran utilizados con frecuencia por los habitantes del sector. Según sus evocaciones manifestadas en las entrevistas, las personas del barrio interactuaban entre familias al igual que con las demás personas que solían frecuentar el sector. Algunos habitantes declaraban que existía para entonces una Junta de Acción Comunal (JAC) que velaba por el cuidado de los diferentes equipamientos del barrio, así como por la creación y promoción de actividades lúdicas y cívicas, que, según los relatos, tenían la función principal de congregar los vecinos del barrio y consolidar los lazos comunitarios.

En parte esta dinámica fue decayendo en virtud de la llegada al barrio de nuevos vecinos, habitantes de las unidades habitacionales de construcción más tardía. Los recién llegados no necesariamente se articulaban a la lógica de integración prestablecida. Según las versiones de los entrevistados, el debilitamiento en la integración comunitaria tuvo sus consecuencias en el mantenimiento de los espacios públicos.

Esto coincide en los relatos de los pobladores con una ruptura en la dinámica del sector, particularmente referida a los usos del espacio público. Según lo manifestado por un entrevistado, "las cosas fueron cambiando; con el paso de los años el sector dejó de ser lo que era”. El espacio vivido, el que autores como Lefebvre (2000) o Monnet (2000) conciben como el espacio que es apropiado por diferentes grupos humanos, donde los sujetos construyen sus experiencias en la cotidianidad, en este caso se transformó. El arribo de nuevos vecinos al sector confrontó a los antiguos habitantes del sector a nuevos vecinos, que eran en esencia desconocidos. Lo anterior es problemático, si entendemos que la experiencia cotidiana del espacio vivido se fundamenta en la idea de la familiaridad: espacio físico familiar, mismo equipamiento, mismas calles; sujetos del sector familiares, antiguos vecinos, participantes del mismo tipo de actividades; temporalidades familiares, usos del espacio en ritmos idénticos. Al

\footnotetext{
${ }^{2}$ Según el censo realizado por el líder comunal Jairo Galvis Giraldo en el mes de junio 2008, existían 1206 habitantes, de los cuales 833 eran adultos, 168 eran jóvenes adolescentes y 205 niños. Por otra parte existían 172 casas construidas y 152 apartamentos. (información extraída de un folleto realizado por la JAC del barrio Santos en el 2008).
} 
llegar los vecinos que no se integran a la dinámica comunitaria se integran al espacio vivido, bajo un conjunto de ideas que los encasillan como diferentes. La representación del otro, la alteridad como se suele entender en la antropología, cuando se refiere a desconocidos, puede implicar su estigmatización.

Los humanos cuando desconocen al otro, a un nuevo vecino, a un recién llegado, por ejemplo, éste puede resultar sospechoso, peligroso por desconocimiento y por la diferencia que esto supone (Carrión, s. f.; Dammert, 2004). Cuando el otro se torna familiar y es integrado en una comunidad, se borran los límites que definen la diferencia, empieza a ser de los "nuestros". En el caso del barrio Santos, además de llegar otros vecinos, llegaron vecinos que usaban el espacio público del parque en otros horarios, en las noches por ejemplo, y no necesariamente para practicar deporte. Tampoco eran niños. Lo anterior tuvo lugar en un periodo de decadencia de la actividad comunitaria en el sector, lo cual se tradujo en la casi desaparición de actividades organizadas en el parque y en el desmejoramiento del equipamiento urbano, ante la ausencia de la actividad comunitaria para su mantenimiento y la insuficiencia de la administración municipal para mantenerlo en condiciones apropiadas. Se materializó así un deterioro, que tuvo su impacto en la valoración simbólica de un espacio que por dejar de obedecer a los usos designados que tenía en su tiempo de "novedoso", se tornó en "obsoleto".

Las referencias en los discursos de los habitantes del sector hablan de una transición de un espacio familiar a uno no amigable y en cierta parte resistido por la gente del sector. Estas narraciones sobre el cambio experimentado por el sector coinciden con las observaciones etnográficas: en efecto, en una parte importante del periodo de observación en el parque no era habitual ver los niños y niñas jugando. Tampoco eran observables las evocadas reuniones, festivales o los innumerables torneos de futbol referidos en los discursos de los habitantes del sector.

Algo que si resultaba frecuente evidencia en ese periodo de observación (e incluso al final) era personas que sacaban a pasear sus mascotas, generando la sensación de que aquel espacio público es apropiado para llenarlo de excrementos animales, no siempre recogidos por sus amos. También ha sido frecuente apreciar a diferentes grupos de jóvenes calificados por los habitantes del sector como "desocupados", como "muchachos perdiendo el tiempo" o "vagos".

En los discursos de los habitantes se escucha con regularidad que este escenario se convirtió en foco de consumo de sustancias psicoactivas. Durante la primera fase de trabajo de campo era común acceder a versiones que asociaban dicho espacio y sus usuarios habituales con representaciones de lo ilegal, lo prohibido, lo fuera de la norma. Una de las entrevistadas manifestaba que solía visitar los espacios públicos como mínimo una vez al día, acompañada de su nieta que se divertía haciendo uso de los espacios verdes y de las zonas de juego, mientras ella limpiaba el parque, recogía las basuras. Relataba que en algunas ocasiones cuando llegaba, el lugar se encontraba ocupado por personas que, a su juicio, no hacían "buen uso" del mismo. 
Según esta narradora, el problema radicaba en que las personas utilizan el espacio para traer a las mascotas a hacer sus necesidades sin tomarse la molestia de recoger sus excrementos. A lo que agregaba que los jóvenes, en lugar de "divertirse sanamente, hacer deporte, o simplemente jugar con los amigos", utilizan el espacio como lugar para el consumo de "vicio". Lo anterior lo presentaba como la principal razón para dejar de visitar el parque con su nieta.

De las observaciones derivamos que en efecto los usuarios del parque eran muy pocos e inconstantes. A grandes rasgos se notaba la soledad del lugar, al igual que el desmejoramiento del equipamiento. Según la comunidad algunos de los equipamientos infantiles fueron hurtados por habitantes de la calle y los que sobrevivieron no estaban en el mejor estado, lo que imposibilitaba o incidía en la poca intensidad de su uso. Por otra parte, eran evidentes las basuras y materia fecal de perro por casi todo el sector. Los escenarios deportivos como canchas al igual que el parque se encontraban en muy mala condición, las mallas estaban agujereadas y las paredes que las sostienen, aún en la actualidad, se están desmoronando, los desagües que poseen se encuentran tapados, en conclusión, es un escenario que ha sido tocado por el olvido y el deterioro. Esta situación de deterioro del espacio físico y la degradación de las formas sociales a través de las cuales se practica el espacio han coincidido para que sea valorado como “obsoleto". En términos del uso social del espacio, se destacan dos razones. La primera radica en la pérdida de compromiso, de interés y apropiación de los habitantes del barrio, quien en cabeza de su junta de acción comunal ha descuidado los sectores públicos comunales. Y la segunda se debe a la presencia de personas -con prácticas catalogadas como no convencionales- que hacen un uso diferencial del espacio, lo que genera tensiones entre quienes utilizan el mismo.

\section{Segundo momento: la voluntad de revitalizar el espacio a través de la acción colectiva}

Pasado un buen tiempo de trabajo de campo, empezamos a percibir que las dinámicas en el sector no variaban mucho y que las acciones colectivas para intervenir el parque eran prácticamente inexistentes. Al tiempo nos enteramos de la conformación de una nueva JAC que llevaba tan solo dos meses de funcionamiento, la cual, según algunos de sus líderes, tenía la intención de generar pertenencia y trabajar por los habitantes del barrio. Un habitante en particular y líder de la JAC, Wilmar, un hombre de unos treinta años, procedente de otra ciudad, emprendió un proyecto con la intención de transformar las dinámicas de apropiación del espacio público del parque. Su iniciativa era recuperar los usos convencionales del parque, por parte de los habitantes convencionales de este tipo de escenarios. Su motivación la encontraba en su propia experiencia de vida en la que, según él, este tipo de canchas en su niñez habían participado en su formación en torno a valores morales y de ciudadanía que lo alejaban de aquellos que prevalecen entre los usuarios no convencionales que son calificados de viciosos. Intentó entonces replicar una experiencia que había tenido en la ciudad de Bogotá: 
la creación de un colectivo de niños y jóvenes, que con el apoyo de sus padres, emprendieran actividades que aporten en la generación de una "visión de vida diferente, basada en el deporte, el estudio, pero sobre todo, en la pertenencia con el barrio y con sus escenarios públicos" (Wilmar, comunicación personal, 5 de agosto de 2017).

Pasados los días del encuentro con este habitante empezarón aparecer carteleras realizadas por la junta de acción comunal que invitaban a participar de la creación de una escuela de futbol popular en el barrio. Al principio la aceptación era muy poca, la gente no creía que hubiera alguien dispuesto a donar su tiempo para este proyecto, además de que pensaban que el sector era un lugar peligroso, donde solo mantenían personas no muy deseables.

Sin embargo, con el pasar de los días, las actividades de práctica deportiva empezaron a ser frecuentadas por niños y niñas quienes participan activamente de las mismas, tanto así que empezó a circular el rumor sobre que en el parque había un joven que era profesor y que estaba enseñándole a los niños del barrio a jugar futbol. En torno a este proyecto, de un individuo respaldado por la acción colectiva de la JAC, se empezó suscitar un mayor interés en la comunidad por saber sobre el proyecto deportivo, sobre quién lo lideraba, algo que tuvo su efecto a la postre en la incorporación de un número mayor de participantes que revitazaban el espacio a través de la restitución de su uso convencional.

Ese interés incidió en la moderación de los prejuicios existentes sobre el parque. Eso no significaba que los usos no convencionales desaparecieran. De lo que se podría hablar es de una redefinición de los tiempos en los que los usuarios convencionales y no convencionales practicaban este espacio público. No hubo un acuerdo explícito, ni un diálogo para que esto se diera. A pesar de eso, la valoración simbólica de los habitantes en general sobre este espacio no está asociada de manera unívoca con nociones socialmente negativas próximas al peligro, al deterioro, a la vagancia.

Es necesario señalar, no obstante, que el proyecto deportivo que se ha ido consolidando tuvo un duro inicio. Al principio solo participaban algunos niños y niñas, pero con el pasar del tiempo se empezaron a involucrar los padres de familia y la comunidad en general.

Algunas de las acciones derivadas de este proyecto y de otras iniciativas de la JAC, se han traducido en intervenciones físicas sobre el espacio en cuestión. Por ejemplo, se suelen organizar brigadas de embellecimiento y de recolección de basura. Asimismo se ha dado inicio a clases de aeróbicos una vez por semana y, de la misma manera, se ha promovido la conformación de una escuela deportiva popular acompañada de un torneo de futbol que busca la integración de todos los habitantes del sector. 
Dichas acciones colectivas de apropiación en torno a los usos convencionales, han alejado formas de valoración que inciden en la manera en que los actores se apropian del espacio público. Ahora no es evaluado como un entorno inseguro o como foco para el consumo de sustancias psicoactivas. Pareciere que el lugar está recuperando la vida que poseía antes a través del restablecimiento de los usos convencionales.

A pesar de que aun el escenario tiene la presencia de actores considerados por los actores que se aglutinaron en torno a las JAC como no gratos debido a las prácticas no convencionales que fomentan, a lo que se le suma que la recuperación y puesta de los escenarios públicos se manifiesta con lentitud, en la actualidad es perceptible una apropiación del espacio más incluyente. En esta última línea, vale la pena destacar que a pesar de la inexistencia de acuerdos explícitos entre los usuarios de usos convencionales y no convencionales, el parque se ha tornado en un espacio donde tienen expresión diversas maneras de apropiación, del ejercicio de la ciudadanía desde concepciones morales divergentes.

\section{Dicusión}

Como bien lo señala una tradición de los estudios territoriales, la producción del espacio está determinada por las relaciones sociales (Lefebvre, 2000). El espacio público, por su carácter compartido, constituye el epítome de esa expresión de colectividad. Pero referir colectividad no significa un acuerdo para apropiar el espacio bajo los mismos supuestos morales ni simbólicos. Así las cosas, las conductas asociadas a las formas divergentes de apropiación espacial se corresponden a principios culturales de acción que pueden marcar una distancia entre los actores que se apropian, y aún de quienes diseñan y construyen materialmente el espacio público, a través de ciertas consideraciones que constituyen geografías morales. Las geografías morales se concretan en los repertorios de las categorías a través de las cuales es valorado un espacio, sometido a juicios y prejuicios que pueden calificarlo como deseable, indeseable, peligroso, eficiente, higiénico, etc., y obviamente incidir sobre la práctica que tiene lugar en este (Hernández, 2016). A pesar de que los planificadores tienen un papel central al asignar valores morales asociados a usos convencionales del espacio público urbano, los diferentes grupos e individuos que se los apropian también le atribuyen esa carga en virtud de sus propios repertorios y trayectorias construidas a lo largo de su experiencia social, la cual define usos prototípicos que deben hacerse de ciertos espacios.

A través de la acción, mediada por los repertorios morales, las personas y las colectividades transforman el espacio, dejando en él su "huella", es decir, señales y marcas cargadas simbólicamente. Como es señalado por Vidal y Pol (2005) "las acciones dotan al espacio de significado individual y social, a través de los procesos de interacción” (p. 283). Así, además de los valores atribuidos subjetivamente al espacio, por su configuración o por nuestra experiencia de lo que debe ser un espacio (algo así como la convicción de que un parque sirve para la lúdica, 
el ocio sano y saludable), este también es valorado en función de las acciones que solemos ver ejecutarse en éste, lo cual puede matizar esa valoración. Así las cosas, un parque puede no ser interpretado de acuerdo a las expectativas convencionales como un espacio para el esparcimiento sano, sino como un foco de caos, de peligrosidad o de vagancia si es practicado por actores, otros, a los que se les estigmatiza o juzga en función de esos valores.

En este último sentido enfatizamos la manera cómo al evaluar simbólicamente un parque, estamos haciéndolo en función de los usos, la práctica o la acción que en este ejecuta otro. Braudillard y Guillaume (2015), consideran que con la modernidad entramos en la era de la producción del otro. Según estos autores, la alteridad empieza a faltar y es imperiosamente necesario producir al otro como diferencia a falta de poder vivir la alteridad como destino. Lo mismo pasa con el espacio público, es producido como diferencia, en ocasiones los límites y dimensiones de un espacio público suelen ser muy confusos, y suelen estar en función de las intenciones de los usuarios, que a su vez son construidos como otros, a veces indeseables, peligrosos o a veces como otros próximos, susceptibles de incluir en una idea colectiva de "nosotros".

Por otra parte, la propia complejidad de la noción de ocio (Uría, 2001) y su dificultoso aislamiento de otras actividades sociales - las simples prácticas recreativas, la sociabilidad o el ejercicio asociativo, por poner algún ejemplo - hace que la materialización de sus escenarios aparezca como una realidad, no pocas veces, problemática. Lejos de constituir territorios neutros, los espacios públicos en donde se desarrolla el ocio no son más que construcciones de actores sociales que reflejan y reproducen en su lógica la misma estructura social y las estructuras morales, como lo hemos señalado atrás. Son también estos espacios el escenario de las resistencias frente al poder, a la vez que componentes que retrasan o estimulan la dinámica social; indican, en fin, la evidencia de una estandarización que invade los reductos más banales y cotidianos, como un parque que se piensa para un tipo de ocio (asociado a usos convencionales), excluyendo otras formas de ocio (no convencionales).

Las huellas dejadas por los usuarios de un espacio público a través de la realización de usos o prácticas no convencionales, asociadas a juicios morales descalificados socialmente, participan en la definición de fenómenos como la "obsolescencia territorial". De la misma manera, el restablecimiento de prácticas convencionales en un espacio que fuera considerada "degradado" "deteriorado" u obsoleto" genera una dinámica que puede ser calificada como de "rehabilitación simbólica” (Althabe, 1993) o de "revitalización territorial”.

Para el propósito de esta discusión, el deterioro es entendido como un presupuesto, que se refiere menos a una cualidad inherente a los elementos a los que se aplica (el espacio, un artefacto, el cuerpo humano, una vida o un período de tiempo) y más bien al producto de un 
proceso cognitivo ${ }^{3}$ La consideración anterior, como los señala Hutchins, desde la perspectiva de la cognición distribuida,

\begin{abstract}
Estriba en el reconocimiento de las formas y contenidos transaccionales entre los elementos involucrados. En este sentido, ni los fenómenos cognitivos, ni las características estructurales de los entornos materiales y sociales en los que estos operan, funcionan como dominios de fenómenos independientes (Bateson, 1982). Más bien, el sistema cognitivo humano puede ser concebido como "un sistema distribuido que trasciende los límites del cerebro y el cuerpo (Hutchins como se citó en Lozano, 2014, p. 156).
\end{abstract}

Dicho de otra forma, podría sugerirse que la reducción del uso y la transformación de la finalidad desde la práctica misma de los espacios públicos, pueden incidir sobre el carácter "obsoleto" del espacio apropiado, es decir, del territorio en términos cognitivos. La obsolescencia territorial ha sido entendida por algunos autores como "un producto de procesos cognitivos, [que] se define por la oposición en su diferencia a la utilidad potencial o fáctica de algo para objetivos fijados convencionalmente" (Lozano, 2014). En virtud de los argumentos anteriores, el espacio público puede ser obsoleto en función de procesos de orden cognitivo como representaciones, percepciones y concepciones. Obviamente estos procesos cognitivos se entienden en función de su anclaje cultural y espacial. Como se colegiría de lo argumentado por ciertos autores (Lynch, 2005; Douglas, 1973; Bataille, 2003), la condición situada -que es indispensable culturalmente para definir lo que es no funcional o está fuera de lugar- no es precisamente una cualidad intrínseca, en este caso, del espacio público definido de antemano, sino más bien el resultado de operaciones de atribución de significado, es decir, dotarlo de valor simbólico como positivo-negativo, útil-inútil, apropiado-inapropiado, funcional-disfuncional, etc.

Sin embargo, consideramos que una lectura de la valoración de un espacio como un producto enfáticamente cognitivo no es suficiente en nuestro análisis. La práctica o los usos del espacio público inciden sobre la dinámica que ésta presenta. En el caso analizado, los usos no convencionales fueron centrales para asignarle características al espacio público, que incidieron en la interpretación de "deteriorado" u "obsoleto" que hicieron de éste algunos habitantes. Desde esta perspectiva, se argumenta que la acción individual y colectiva que se manifiesta en los usos le confiere ciertas propiedades al espacio que posteriormente son integradas a los procesos cognitivos, a través de los cuales se interpreta un espacio público.

\footnotetext{
3 "Se ha postulado que la cognición se encuentra inextricablemente vinculada no sólo con el funcionamiento del sistema nervioso, sino también con las especificidades del entorno ecológico, de modo tal que "el entendimiento de los fenómenos cognitivos debe incluir una consideración sobre los entornos en los que los procesos cognitivos operan y se desarrollan” (Hutchins como se citó en Lozano, 2014, p. 156).
} 
Esa acción sobre todo cuando es colectiva que se sujeta a diferentes repertorios morales asociados a usos convencionales o no convencionales del espacio, no solamente sirve para generar estigmas sobre el espacio o formas de valoración negativas como la de deteriorado u obsoleto. Así tiene lugar lo que en nuestro análisis entendemos como un proceso de revitación del espacio. Entendemos por "re-vitalizar (dar más fuerza y vitalidad a una cosa) al tener un sentido de aumento, progresivo e integrador" (Yague, 2009, p. 2); en este caso, un mayor sentido de la vida social, de los usos por individuos y grupos cada vez más numerosos y diversos, de lo que antes fuera un espacio "obsoleto".

\section{Conclusiones}

A lo largo de las dos últimas décadas el espacio público del barrio Santos ha vivido un intenso proceso de reestructuración y transformación física, simbólica, social y funcional. Durante este periodo, el sector ha pasado de una novedad vital en su uso y en las representaciones de sus practicantes al deterioro, y al declive en sus usos que puede ser interpretada como obsolescencia territorial”, para posteriormente ser objeto de una revitalización, como consecuencia de los usos colectivos que incidieron sobre la forma de evaluarlo.

Las cuestiones referentes al espacio público urbano, a sus dinámicas de declive de revitalización urbana incumben no solamente a un barrio, sino a la ciudad en su conjunto. Lo anterior considerando que las ciudades presentan una gran parte de su extensión en espacios públicos. Estos son escenarios de encuentro, de confrontación simbólica donde además se escenifica la ciudadanía. Estos pueden ser “abandonados” por unos grupos y reinvidincados por otros en un cierto periodo de tiempo. Lo anterior supone que cuando es usado por unos puede ser valorado como negativo por los otros y viceversa. En algunos momentos, sin la existencia de acuerdos, un espacio puede usarse por diferentes grupos en función de sus propios intereses y de sus referentes culturales y morales.

Las ideas expuestas en este documento proponen una múltiple visión del espacio público. Por una parte, una aproximación cognitiva y simbólica que remite a las valoraciones que hacen de un espacio público un escenario vital o decadente. Por otro lado, una aproximación a través de las relaciones sociales y de las acciones que producen además de una forma particular de espacio, una idea sobre el otro que se lo apropia, el otro que es juzgado, poniendo en juego un conjunto de categorías que dan cuenta de ese otro que se encuentran supeditas a ciertas "geografías morales". Finalmente, ofrecemos una aproximación a la acción colectiva que intencionadamente pretende restituir la vitalidad de un lugar, a través de la reinstauración de usos convencionales que gozan de un favor colectivo.

Así pues, un espacio público urbano por pequeño que sea, en este caso un parque, implica un enorme despliegue de acciones sociales que están más allá de la materialidad, implicando la producción de valor simbólico y la apropiación sociopolítica. Lo anterior supondría que 
Obsolescencia y revitalización de un parque. Acción colectiva, cognición y ciudadanía en la apropiación del espacio público

la administración municipal encargada del diseño de este tipo de espacios reconozca la carga ideológica que los construye como espacios que a la vez que resaltan un tipo de actividades convencionales, excluyen a usuarios, también ciudadanos, que se quieren distanciar de esos usos.

En el transcurso de este análisis hemos podido ver como la producción del espacio público (el parque) implica un complejo entramado de relaciones sociales y políticas de actores locales en este espacio, así como de la puesta en funcionamiento de mecanismos de valoración simbólica del espacio por parte de usuarios, transeúntes y vecinos del espacio. Siguiendo esta idea pensamos que se hace necesario reorientar e implementar económicamente las políticas públicas de revitalización y rehabilitación urbana, con el fin de superar la visión reduccionista - de usos convencionales- que aplica el estado a través de la planificación, el diseñamiento y el ordenamiento territorial.

\section{Referencias}

Althabe, G. (1993). Promotion symbolique et logiques sociales. En G. Althabe., B. Legé. y M. Selim. (Eds.), Urbanisme et réhabilitation symbolique. Ivry, Bologne et Amiens (pp. 13-32). Paris, Francia: L'Harmatan.

Bataille, G. (2003). La conjuración sagrada: ensayos 1929-1939. Buenos Aires, Argentina: Adriana Hidalgo Ediciones.

Braudillard, J. y Guillaume, M. (2015). Figuras de la alteridad. Madrid, España: Editorial Aguilar

Burbano, M. A. (2014). La investigación sobre el espacio público en Colombia: su importancia. Revista Territorios, (186), 185-205.

Carrasco, D. (2011). Espacio público y ciudadanía: Nuevos desafíos para la agenda de desarrollo en Chile. Polis. Revista Latinoamericana, 10(30), 19-43.

Carrión, F. (Sin Fecha). Espacio público: punto de partida para la alteridad. Recuperado de file: / / / C: /Users /Usuario/Downloads/1228415744.Espacio_publico._Punto_de_ partida_para_la_alteridad_2.pdf

Dammert, L. (2004). ¿Ciudad sin ciudadanos? Fragmentación, segregación y temor en Santiago. EURE (Santiago), 30 (91), 87-96. https: / / doi.org/10.4067/S0250-71612004009100006

Delgado, M. (2015). El espacio público como ideología. Madrid, España: Los libros de la Catarata.

Douglas, M. (1973). Pureza y peligro: un análisis de los conceptos de contaminación y tabú. Madrid, España: Siglo Veintiuno Editores.

Gamboa, P. (2003). El sentido urbano del espacio público. Bitácora, 7(1), 13-18. 
Goffman, E. (2000). La presentación de la persona en la vida cotidiana. Buenos Aires, Argentina: Amorrortu Editores.

Hernández, G. (2016). Decadencia y apogeo del espacio. Dimensiones culturales del cambio socioeconómico en un caso de renovación urbana en Colombia. Horizontes Antropológicos, 22 (45), 249-278. DOI: https://doi.org/10.1590/S0104-71832016000100010

Janoschka, M. (2002). El nuevo modelo de la ciudad latinoamericana: fragmentación y privatización. EURE (Santiago), 28 (85), 11-20. https://doi.org/10.4067/S025071612002008500002

Santos llegó a sus quince primaveras. (27 de junio de 2013). El tiempo. Recuperado de http: / / www.lapatria.com/manizales/el-barrio- santos-llego- sus-quince- primaveras- 37113.

Lamizet, B. (2002). Le sens de la ville. Paris, France: L'Harmattan.

Lefebvre, H. (2000). La production de l'espace. Paris, France: Anthropos.

Low, S. M. (2009). Cerrando y reabriendo el espacio público en la ciudad latinoamericana. Cuadernos de Antropología Social, (30), 17-38.

Lozano, C. (2014). Deterioro urbano y cognición: hacia un análisis de los espacios fragmentarios. RevistaVirajes, 16 (2), 151-167.

Lynch, K. (2005). Echar a perder: un análisis del deterioro. Barcelona, España: Editorial Gustavo Gili.

Monnet, J. (1998). La symbolique des lieux : pour une géographie des relations entre espace, pouvoir et identité. Cybergeo: European Journal of Geography, (56). DOI: https://doi. org/10.4000/cybergeo. 5316

Monnet, J. (2000). La ville comme OSSI (Object Socio-Spatial Identifiable): Les catégories de l'experience et de la connaissance de l'espace urbain. En J. Monnet. y G. Capron. (Eds.), L'urbanité dans les Amériques. Le processus d'identification socio-spatiale (pp. 17-39). Toulouse, Francia: Presses Universitaires du Mirail.

Obando, L. y Salcedo, M.A. (2015). Los parques: sus usuarios y su sentido social en la vida urbana. Una mira desde los usuarios típicos de dos parques de la ciudad de Cali. Revista de Antropología y sociologíaVIRAJES, 17 (2), 37 - 54.

Páramo, P. y Burbano, M. A. (2014). Los usos y la apropiación del espacio público para el fortalecimiento de la democracia. Revista de arquitectura, 16, 6-15.

Páramo, P. y García, M. (2010). La dimensión social del espacio público: aportes para la calidad de vida urbana. Bogotá, Colombia: Ediciones Universidad Pedagógica Nacional y Universidad Santo Tomás. 
Páramo, P. y Arroyo, A. M. B. (2014). Los usos y la apropiación del espacio público para el fortalecimiento de la democracia. Revista de arquitectura, 16, 6-15.

Piveteau, J. (1995). L'espace urbain : imaginaires et faits têtus. En J. Piveteau. (Ed.), Temps du territoire: continuités et ruptures dans la relation de l'homme à l'espace (pp. 127-145). Genève, Suisse: Ed. Zoé.

Salcedo, R. (2002). El espacio público en el debate actual: Una reflexión crítica sobre el urbanismo post-moderno. Eure (Santiago), 28 (84), 5-19.

Uría, J. (2001). Lugares para el ocio. Espacio público y espacios recreativos en la restauración española. Historia social, 18, 89-111.

Vidal, T. y Pol.E. (2005). La apropiación del espacio: una propuesta teórica para comprender la vinculación entre las personas y los lugares. Anuario de psicología, 36(3), 281-297.

Yague, J. M. (2009). Revitalización vs Rehabilitación. En Consejo General de Arquitectura Técnica de España, Rehabilitación y Sostenibilidad. El Futuro es Posible. Congreso llevado a cabo en Barcelona, España. 